\title{
Corrigendum: In situ targeted MRI detection of Helicobacter pylori with stable magnetic graphitic nanocapsules
}

Yunjie Li, Xiaoxiao Hu, Ding Ding, Yuxiu Zou, Yiting Xu, Xuewei Wang, Yin Zhang, Long Chen, Zhuo Chen $\&$ Weihong Tan

Nature Communications 8:15653 doi: 10.1038/ncomms15653 (2017); Published 15 Jun 2017; Updated 30 Aug 2017

Supplementary Fig. 4 of this Article contains errors. Supplementary Fig. $4 \mathrm{c}$ shows the $\mathrm{T}_{2}$-weighted phantom images in reverse order, and Supplementary Fig. $4 \mathrm{~d}$ is a duplicate of Fig. 3d. The corrected version of Supplementary Fig. 4 is shown below as Fig. 1.

Open Access This article is licensed under a Creative Commons Attribution 4.0 International License, which permits use, sharing, adaptation, distribution and reproduction in any medium or format, as long as you give appropriate credit to the original author(s) and the source, provide a link to the Creative Commons license, and indicate if changes were made. The images or other third party material in this article are included in the article's Creative Commons license, unless indicated otherwise in a credit line to the material. If material is not included in the article's Creative Commons license and your intended use is not permitted by statutory regulation or exceeds the permitted use, you will need to obtain permission directly from the copyright holder. To view a copy of this license, visit http://creativecommons.org/licenses/by/4.0/

(C) The Author(s) 2017 

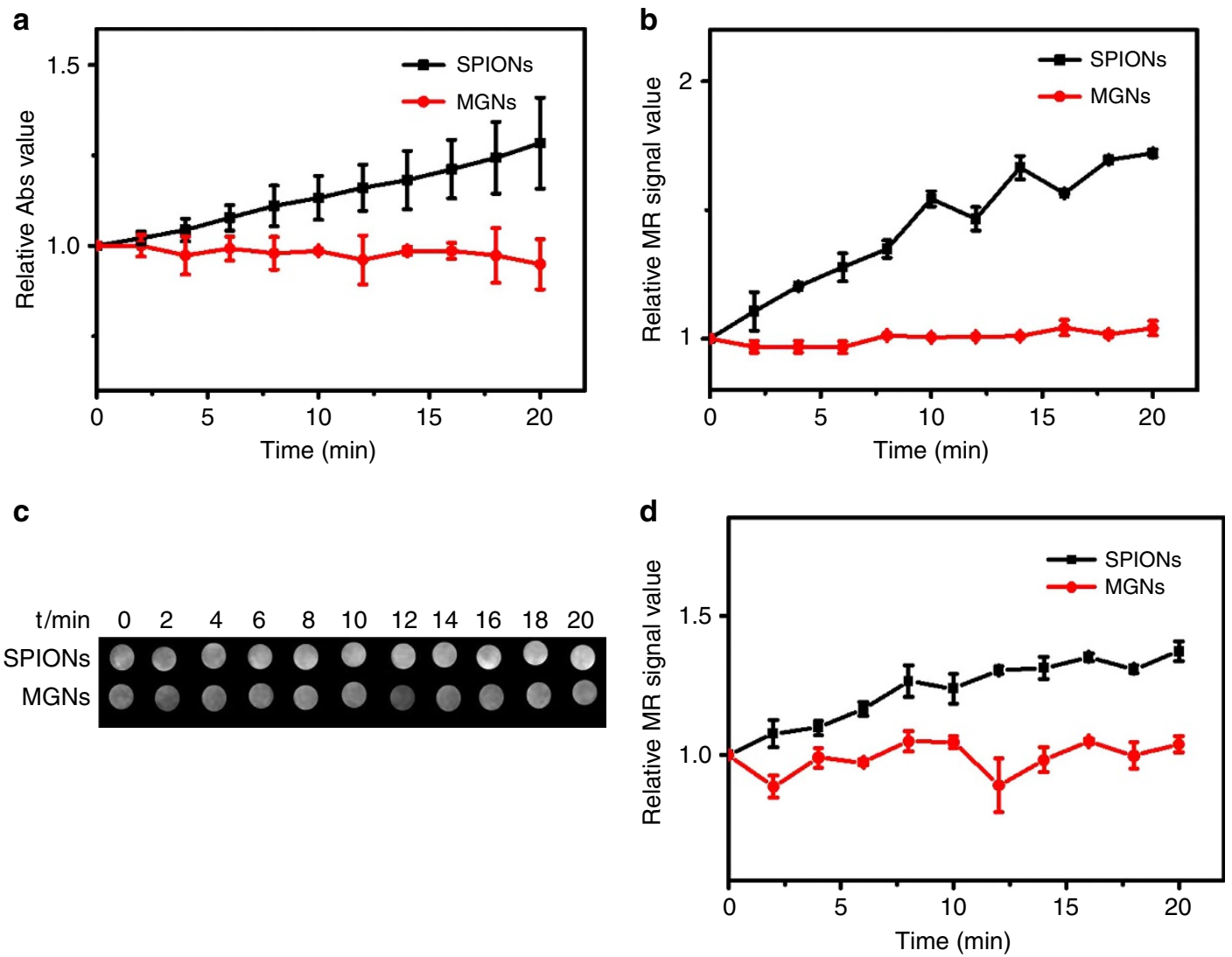

Figure 1 